\title{
O ecossistema da Ciência Aberta
}

\section{The Open Science ecosystem}

\author{
Fabiano Couto Corrêa da SILVA' (iD 0000-0003-4247-3810 \\ Lúcia da SILVEIRA² (iD 0000-0003-1118-2121
}

\begin{abstract}
Resumo
O presente estudo descritivo tem como objetivo apresentar as dimensões da Ciência Aberta e o impacto desse contexto na vida dos pesquisadores. O surgimento de revistas científicas no século XVII ajudou a promover a Revolução Científica, permitindo que os pesquisadores se comunicassem através do tempo e do espaço usando as tecnologias da época para gerar conhecimento confiável de maneira mais rápida e eficiente. Aproveitando os contínuos avanços nas tecnologias da informação, os pesquisadores estão caminhando para um novo ecossistema científico, o qual é mais aberto para acompanhar o ciclo de vida investigativo. É nesse contexto que a Ciência Aberta surge para garantir a disponibilidade e a usabilidade sem barreiras de acesso às publicações acadêmicas e aos dados resultantes de pesquisas e metodologias acadêmicas, incluindo códigos ou algoritmos que foram usados para gerar esses dados.
\end{abstract}

Palavras-chave: Acesso Aberto. Ciência Aberta. Ecossistema.

\begin{abstract}
The present study shows the dimensions of open science and the impact of this context on researchers' lives. The birth of scientific journals in the seventeenth century helped to promote the Scientific Revolution, allowing researchers to communicate through time and space, using the technologies of the time to generate reliable knowledge more quickly and efficiently. Taking advantage of continuous advances in information technology, researchers are moving towards a new, more open scientific ecosystem to accompany the research life cycle. It is in this context that Open Science arises to ensure the free availability and usability of academic publications, data resulting from research and academic methodologies, including codes or algorithms that were used to generate such data.
\end{abstract}

Keywords: Open Access. Open Science. Ecosystem.

\section{Introdução}

No passado, as inovações dos cientistas eram subsidiadas por pessoas ricas. À medida que a ciência foi se tornando cada vez mais importante para a evolução da sociedade, os investimentos destinados ao avanço científico foram aos poucos sendo institucionalizados por meio de interesses governamentais, sociais e empresariais, principalmente pelo fato de que a ciência tornou-se um ativo competitivo no contexto capitalista. Se antes era a

\footnotetext{
1 Universidade Federal do Rio Grande do Sul, Faculdade de Biblioteconomia e Comunicação, Programa de Pós-Graduação em Ciência da Informação. Av. Paulo Gama, 110, Farroupilha, 90040-060, Porto Alegre, RS, Brasil. Correspondência para/Correspondence to: F.C.C. SILVA. E-mail: <fabianocc@gmail.com>.

2 Universidade Federal do Rio Grande do Sul, Departamento de Comunicação, Programa de Pós-Graduação em Comunicação. Porto Alegre, RS, Brasil. Recebido em 8 de março de 2019, versão final reapresentada em 13 de maio de 2019 e aprovado em 26 de junho de 2019
}

Como citar este artigo/How to cite this article

Silva, F.C.C.; Silveira, L. O ecossistema da Ciência Aberta. Transinformação, v.31, e190001, 2019. http://dx.doi.org/10.1590/2318-0889201931e190001 
economia que fomentava a ciência, agora a ciência é que oferece subsídios para o crescimento da economia. Não se inova sem ciência, tampouco se evolui sem ela³.

Assim, ter acesso à informação científica tornou-se primordial para a construção de novos conhecimentos científicos. Para acompanhar os rápidos avanços da ciência, são necessárias novas concepções de sua formalização, pois os moldes existentes já não suprem mais as necessidades dos pesquisadores perante a Sociedade da Informação. Dessa maneira, tornou-se imprescindível que os canais formais de comunicação, como, por exemplo, o periódico, sejam ressignificados dentro das diversas possibilidades que a Internet e as ferramentas da Web proporcionaram ao mundo da informação e da comunicação humana.

Até o ano de 2003, é estimado que a civilização tenha produzido cerca de cinco exabytes de informação; de modo bastante distinto, estima-se que, atualmente, graças à Internet, essa informação passou a ser produzida em apenas dois dias (Schmidt; Cohen, 2013). Em razão do surgimento de plataformas e redes colaborativas abertas, a dependência sobre a distribuição de informações pelos intermediários comerciais deixou de ser a única via possível para a comunicação científica, economizando, assim, uma grande quantidade de recursos.

É nesse contexto que o velho modelo de negócios dos editores científicos começou a falhar, pois se percebeu que os produtores de informação não precisavam comercializá-las para garantir sua legitimidade e sua distribuição mundial. O próprio sistema estruturado de comunicação científica já compreende isso e o faz continuamente.

No entanto, somente com os recursos provenientes da Internet é que os envolvidos na produção científica construíram um novo modelo para publicação de suas pesquisas, passando a assumir novamente a responsabilidade de publicação de pesquisas. Apesar de haver conservadorismo, os pesquisadores agora têm mais alternativas do que nunca para evitar esses problemas. A ciência é feita para ser aberta e, de fato, beneficia-se quando não ocorrem restrições. Ela está descobrindo novas alternativas para que todos os envolvidos - comunidade científica e sociedade -, possam aproveitar, sem ter de pagar por isso novamente. Isso culmina em uma evidência já em prática: a Ciência Aberta deve ser o futuro.

\section{O que é Ciência Aberta?}

A discussão sobre conhecimento aberto passa por vários campos, que vão desde a economia até as práticas culturais. Quando se está convencido de que o conhecimento aberto é uma condição fundamental para promover a inovação e a criatividade, torna-se necessário rever criticamente as políticas, as decisões e as práticas que o inibem em todos os níveis e dimensões sociais. Uma dessas dimensões é a que diz respeito à ciência, um campo nodal dentro da chamada Sociedade da Informação, uma vez que constitui o fundamento da atual acumulação de capital.

A Ciência Aberta é um movimento que incentiva a transparência da pesquisa científica desde a concepção da investigação até o uso de softwares abertos. Também promove esclarecimento na elaboração de metodologias

2 e gestão de dados cientíícos, para que estes possam ser distribuídos, reutilizados e estar acessíveis a todos os níveis da sociedade, sem custos. Propõe, ainda, a colaboração de não cientistas na pesquisa, ampliando a participação social por meio de um conjunto de elementos que dispõem de novos recursos para a formalização da comunicação científica.

Nesse contexto, Bartling e Friesike (2014) propõem cinco escolas de pensamento sobre Ciência Aberta: a Escola de Infraestrutura, que lida com a arquitetura tecnológica; a Escola Pública, que se refere à acessibilidade da criação de conhecimento, incluindo o cidadão para o desenvolvimento de pesquisas; a "Escola das Métricas", que se refere à medição do impacto alternativo; a "Escola Democrática", que trata do acesso ao conhecimento como um

\footnotetext{
3 Informação oral da pesquisadora Maria Nélida Gonzalez de Gomes em "Os estudos da informação e os sistemas de avaliação científica e de responsabilização", no evento "Debatendo ações, aplicações e teorias voltadas à Ciência da Informação", ocorrido em Florianópolis, SC, Brasil em 2018.
} 
direito humano, principalmente quando a pesquisa tem financiamento público; e, por fim, a "Escola Pragmática", que se ocupa da pesquisa colaborativa, incluindo a inovação aberta.

Silva et al. $(2017$, p.4) propõem um modelo de comunicação científica que prevê os elementos da Ciência Aberta desde o início da pesquisa, por meio das novas práticas de compartilhamento. No processo tradicional, o compartilhamento/publicação ocorria principalmente por intermédio de periódicos, teses e dissertações; agora, pode ser feito desde o delineamento da pesquisa, por meio do registro do projeto, da gestão de dados científicos, da publicação em pre-print e da avaliação por pares, todos estes de forma aberta, cujo reconhecimento é baseado em práticas abertas e em sua reutilização pela educação aberta.

Entende-se que a Ciência Aberta modifica o decurso da comunicação e do registro de muitos processos, formalizando várias etapas antes não compartilhadas, como, por exemplo, o registro de projetos de pesquisa e os dados brutos resultantes do trabalho. Esse novo fluxo, dessa maneira, não modifica a essência da pesquisa; sua principal diferença em relação ao processo anterior é a transparência, a reutilização, a colaboração e a inclusão social na produção científica.

\section{O ecossistema da Ciência Aberta}

O ecossistema da Ciência Aberta, dentro da concepção da eScience, torna-se um novo paradigma para a comunicação científica porque são incluídas novas interações entre pesquisadores, instituições de pesquisa, empresas e sociedade. Além disso, há uma transparência em todo processo do ciclo de investigação científica.

Para Anglada e Abadal (2018), a classificação sistemática mais completa para representar a Ciência Aberta é a desenvolvida pelo grupo Facilitate Open Science Training for European Research (Foster), presente no projeto Open Science do Programa Comunitário de Investigação e Inovação, intitulado Horizon 2020. A Taxonomia (Figura 1) reuniu um grupo de elementos que compõe as novas práticas da Ciência Aberta.

De acordo com a plataforma Foster, a Taxonomia de Ciência Aberta representada pelos grandes eixos para o desenvolvimento da Ciência Aberta são, respectivamente, o acesso aberto, os dados abertos e a pesquisa reproduzível, conforme contextualizações a seguir.

\section{Open Science Taxonomy}

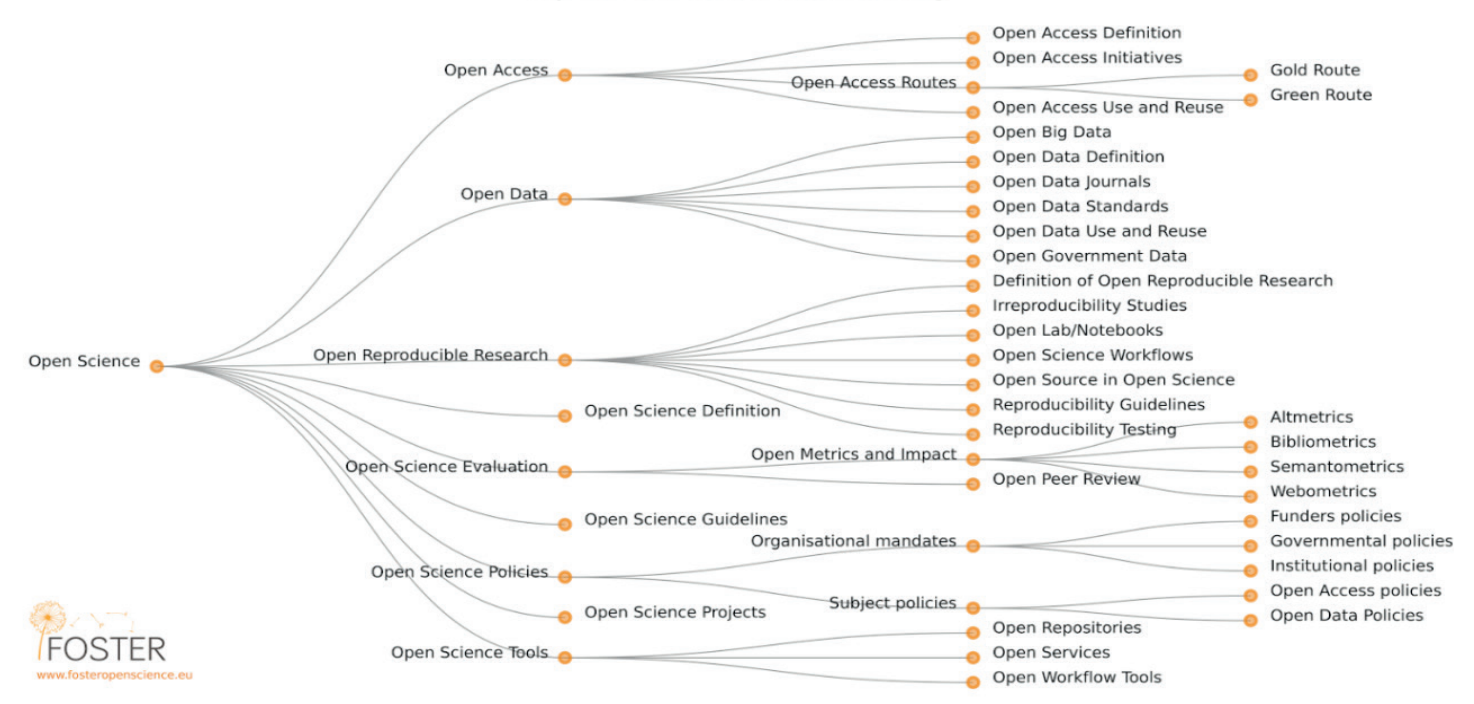

Figura 1. Open Science Taxonomy.

Fonte: Foster (2018) 
Acesso Aberto é um dos movimentos pioneiros no compartilhamento do acesso à informação científica, motivado principalmente pela colaboração internacional dos pares e pelos altos custos do acesso a periódicos de alta qualidade. As recomendações do Acesso Aberto estão amplamente difundidas na Iniciativa de Budapest Open Access Initiative (BOAl, Acesso Aberto de Budapeste), que o define como:

Acesso aberto à literatura científica revisada por pares significa a disponibilidade livre na internet, permitindo a qualquer usuário ler, fazer download, copiar, distribuir, imprimir, pesquisar ou referenciar o texto integral desses artigos, recolhê-los para indexação, introduzi-los como dados em software, ou usá-los para outro qualquer fim legal, sem barreiras financeiras, legais ou técnicas que não sejam inseparáveis ao próprio acesso a uma conexão à Internet. As únicas restrições de reprodução ou distribuição e o único papel para o direito autoral neste domínio é dar aos autores o controle sobre a integridade do seu trabalho e o direito de ser devidamente reconhecido e citado (Budapest Open Access Initiative, 2002, p.1).

Para implementação desse Movimento, dois caminhos foram segmentados de modo a permitir a abertura de acesso, sendo eles o verde e o dourado:

a) Via Verde: é conhecida como um processo de autoarquivamento, no qual o autor da obra submete seu trabalho para um espaço digital chamado de repositório. Possui, normalmente, uma política de gestão institucional que define quais critérios de inclusão documental e de descrição bibliográfica serão realizados. O processo consiste no ato de o autor incorporar o texto final de seu manuscrito em um repositório. Os documentos aceitos dependerão da política de gestão, a qual normalmente abrange: anais de congressos, artigos sem revisão, artigos publicados, teses, dissertações, relatórios etc. Iniciativas de repositórios digitais bem-sucedidas são o Lume, da Universidade Federal do Rio Grande do Sul (UFRGS); a Arca, da Fundação Oswaldo Cruz (Fiocruz); a Rede de Acervos Digitais, da Universidade Autônoma do México (RAD-UNAM); e o RepositóriUM, da Universidade do Minho (Portugal).

b) Via Dourada: é representada pela revista científica criada sob o conceito de abertura de acesso, isto é, trata-se de uma revista a cujos artigos científicos se têm acesso gratuito, seguindo os princípios e valores do acesso aberto. Wilsdon et al. (2018) analisaram que dois terços dos artigos publicados entre 2011 e 2014 nos Estados Unidos estão em acesso aberto; no Brasil, considerado uma potência em iniciativas de publicações periódicas em acesso aberto, são cerca de 75\%. Uma das experiências bem-sucedidas é a Scientific Electronic Library Online (SciELO). Outras ações oriundas das universidades são os Portais de Periódicos institucionais, que, quando consolidados, têm como principal função dar condições de melhoria para as revistas atingirem a qualidade editorial. Exemplos na América Latina são o Portal de Revistas, da Universidade Católica do Uruguay, o Revistas, da Universidade Nacional de Córdoba (Argentina), o Portal de Revistas Acadêmicas, da Costa Rica, o Portal de Revistas Acadêmicas, da Universidade do Chile, o Portal de Revistas, da Universidade de Lima (Peru); no Brasil, somam-se mais de 100 portais, dentre eles, o Portal de Periódicos UFSC, da Universidade Federal de Santa Catarina (UFSC), o Portal de Periódicos Eletrônicos Cientíicos Unicamp, da Universidade Estadual de Campinas (Unicamp), o Portal de Revistas USP, da Universidade de São Paulo (USP) e o Portal de Periódicos Fiocruz.

c) Periódicos híbridos: são as revistas com acesso gratuito ao seu conteúdo, mas que exigem taxas daqueles que intentam enviar estudos com o propósito de publicar (Article Processing Charge [APC]); por exemplo, o autor paga certa quantia (cerca de 6 mil reais, em média, para as revistas internacionais, dependendo da área) para que o artigo possa ser avaliado e, possivelmente, publicado.

O modelo de negócio tradicional de publicação de periódicos, conhecido como modelo de subscrição (subscription business model) ou de acesso restrito às fontes de informação, não é considerado uma iniciativa de acesso aberto. O processo de publicação é atrelado a uma editora comercial, que recebe no mínimo duas taxas: a de publicação (do autor/da instituição) e a de acesso à obra, já publicada por meio de assinaturas dos periódicos e das bases de dados. No entanto, a editora, em nenhum momento, remunera o pesquisador ou avaliador por sua contribuição. 
Esse modelo baseado em assinaturas tornou-se o "combustível" para o surgimento do Acesso Aberto. Os valores abusivos das assinaturas de bases de dados tornaram impossível a sustentabilidade do acesso à informação, o que culminou na crise de periódicos na década de 1980. A título de conhecimento, em 2019, as Taxas de Publicação de um Artigo (APC) na Elsevier custam de US\$500 a US\$5000 (Elsevier, 2019). Esse modelo de negócio gerou um lucro operacional de $£ 942$ milhões, com 2\% de crescimento em relação ao ano de 2017 (Relx Group, 2018).

Nesse sentido, a ação dos envolvidos contra esse oligopólio de editoras foi o Movimento de Acesso Aberto, iniciado por volta de 1999, que agora faz parte de um guarda-chuva maior, a Ciência Aberta. É importante ressaltar que, na região da América Latina, a maioria das revistas científicas digitais é editada por universidades públicas e foi criada dentro da filosofia do acesso aberto.

A segunda dimensão, dados abertos é considerada a disponibilização de dados brutos de pesquisa científica - entendidos como fontes primárias - de forma organizada, sistematizada e registrada em bibliotecas de Open Data (dados abertos) e Linked data (dados vinculados). Silva (2018, p.118) compreende que o "desenvolvimento de dados abertos interligados ainda é incipiente, mas está previsto com grande potencial de cooperação e reutilização de informações entre pesquisadores que compartilham o mesmo objetivo de estudo".

Para realizar esse objetivo, é importante avaliar o grau de abertura de dados. Tim Berners-Lee, inventor da Web e criador da World Wide Web Consortium (W3C), identificou que, para atingir o máximo de abertura de dados, é necessário, inicialmente: publicar na Internet um conteúdo, em qualquer formato, preferencialmente os formatos não proprietários - como CSV, ao invés do Excel -, que contenha uma licença aberta de propriedade intelectual, como a Creative Commons; fazer a publicação estruturada dos dados para a sua reutilização, utilizando Uniform Resource Identifier (URI) bem desenhadas para identificá-los de modo que as pessoas possam referenciá-las, além de seguir os padrões W3C (usando o Resource Description Framework (RDF) e linguagem de consulta SPARQL), apresentando uma identificação única ou URI; e, por fim, os dados precisam estar ligados a outras pessoas ou instituições, promovendo sua inter-relação, o que é chamado de dados vinculados. A Web Semântica, portanto, não está apenas colocando os dados na web. Trata-se de fazer links para que uma pessoa ou uma máquina possa explorar a rede de dados com o propósito de encontrar outros dados relacionados (Berners-Lee, 2006).

Há exemplos interessantes de visualização de dados com esse nível de inter-relação, como o que é apresentado pela emissora de rádio da BBC em seu site sobre os Jogos Olímpicos de Londres, graças às ontologias de sua Linked Data Platform. Convém citar, ainda, o Portal Europeana, biblioteca digital com mais de 10 milhões de itens do patrimônio cultural e científico da Europa, além do site de dados abertos da Biblioteca Nacional da França, que integra e vincula de forma automatizada todos os recursos de informação disponíveis sobre determinado tópico. No Chile, uma das principais referências de dados abertos é o site Open Linked Data, da Biblioteca do Congresso Nacional, proporcionando acesso a normas legislativas, biografias de parlamentares e entidades geográficas da divisão territorial na administração política chilena, entre outros recursos (Silva, 2018).

A terceira dimensão da ciência aberta de acordo com a plataforma Foster, pesquisa reproduzível aberta (Open reproducible research) é o ato de praticar Ciência Aberta e de oferecer aos usuários livre acesso a elementos experimentais para permitir a reprodução da pesquisa, independente dos seus resultados (Foster, 2018; Pontika et al., 2015). Nesse caso, é necessário que o pesquisador que cria ou utiliza informação científica deve fazê-lo com recursos igualmente abertos, preocupando-se em escolher softwares/aplicativos ou métodos que possam ser replicados e reproduzíveis. Os pesquisadores de diferentes áreas chamam isso de crise de reprodutibilidade, que é a dificuldade em recriar a pesquisa de outras pessoas; mesmo com recursos, algoritmos, métodos idênticos, os resultados não eram os mesmos.

Nüst et al. (2018) analisaram um grupo de publicações para avaliar o quanto os artigos de determinada área eram reprodutíveis, levando-se em conta dados, métodos (tipos de análise e processamento), ambiente 
computacional e resultados. Eles constataram que o índice de reprodutibilidade dos 32 documentos analisados era muito baixo e apontaram que os periódicos Vadose Zone Journal, GigaScience e Journal of the American Statistical Association (Jasa) adicionaram, nas orientações para autores, indicações de plataformas nas quais é possível incluir os dados. Essa iniciativa da Ciência Aberta, que teve a adesão dos journals, configura-se como um novo papel a se somar às equipes editoriais e avaliadores, que terão o compromisso de verificar disponibilidade, qualidade e potencial de usabilidade das informações para que, futuramente, outras pessoas possam reutilizar os dados.

Como exemplo de aplicação da reprodutibilidade, algumas áreas, tem utilizado os cadernos Abertos (Open notebook) que pode ser considerado um grau extremo da Ciência Aberta, visto que a pesquisa é compartilhada desde seu início. O principal registro de um projeto de pesquisa (caderno de pesquisa) é divulgado pela Internet, incluindo os dados brutos, casos malsucedidos e atípicos etc. Isso, porém, não é comum, pois muitos cientistas têm receio de mostrar resultados negativos e não positivos. Para que os dados malsucedidos possam ser divulgados, é comum que o editor de periódico deixe explícito nas diretrizes a disponibilidade de recebimento desse tipo de pesquisa.

A quarta dimensão, à Avaliação Aberta (Open Science Evaluation), compreende tanto as metrias alternativas e abertas de avaliação da ciência, como a avaliação por pares aberta. As metrias alternativas estão voltadas para verificar o impacto real e social de uma dada pesquisa, quanto a esse assunto trouxemos alguns apontamentos na seção de interpretação dos antecedentes da ciência aberta. Com relação a promoção da transparência de avaliação por pares aberta, existem 22 maneiras diferentes de fazê-la, especialmente se forem levadas em conta as críticas ao modelo tradicional de avaliação simples ou duplo-cego, como a lentidão, a pouca fidedignidade, a presença de avaliadores que não assumem responsabilidades, a ausência de reconhecimento do trabalho do parecerista etc. Para realizar a avaliação aberta, focaliza-se principalmente a transparência das identidades de autores e pareceristas (interação múltipla), a publicação dos relatórios dos pareceristas e a participação maior do público no processo de revisão. Em relação a esta última maneira, há algumas possibilidades, como (a) abrir o artigo publicado para permitir a interação com o público; e (b) publicar a versão preliminar do manuscrito em plataformas abertas, externas a do periódico, como, por exemplo, o repositório de pre-prints (Ross-Hellauer, 2017; Spinack, 2018).

Dentre as vantagens da avaliação aberta, destaca-se a possibilidade de detectar erros com maior facilidade, de validar descobertas e de aumentar a confiança geral nos resultados publicados. Essa interação "poderia levar a uma melhora na precisão da revisão" (Spinack, 2018, p.1). Um dos receios dos pareceristas-pesquisadores reside na sua exposição diante da área, principalmente quando se é um jovem pesquisador, já que ele pode sofrer represálias dos autores ressentidos (Spinack, 2018; Ross-Hellauer, 2017). De todo modo, o relatório publicado também oportuniza o aprendizado deles.

Apesar disso, 58,8\% do total de mais de 3 mil pesquisadores que participaram da pesquisa de Ross-Hellauer, Deppe e Schmidt (2017) apoiam a publicação aberta dos pareceres, ao passo que 73,4\% dos respondentes acreditam que deve ser uma opção do avaliador abrir sua identidade. Diferentemente do processo tradicional de avaliação às cegas por pares, na aberta a interação entre os envolvidos (autor, parecerista e cidadão) pode ocorrer em qualquer momento, facilitando a comunicação e o processo de construção de novos conhecimentos, inclusive a inovação.

E por último, a quinta dimensão trata das Políticas de Ciência Aberta (Open Science Policies) regulam a abertura da ciência e também estão relacionadas com a abertura de dados da inovação, dos negócios e da pesquisa científica, com o uso e reuso de dados, de publicações, de direito autoral, entre outros. Elas devem estar conectadas às políticas de governo aberto e prever fundos de investimento para alavancar a Ciência Aberta. Em 2017, as principais agências de fomento à pesquisa, como Wellcome Trust, Fundação Bill e Melinda Gates e Horizon 2020, passaram a exigir a formulação de Planos de Gestão de Dados dos projetos que financiam. São exemplos disso os planos nacionais para fomentar a Ciência Aberta, lançados, em 2018, na França e no Canadá. A seguir, será descrito o que foi apontado nesses documentos para, na sequência, ser contextualizada a situação brasileira. 
Na França, o Plano Nacional de Ciência Aberta prevê a necessidade de um diálogo sobre o ecossistema de Ciência Aberta, evidenciando a utilidade para pesquisadores, empresas e cidadãos (France, 2018). Esse plano determina que o Ministério do Ensino Superior de Investigação e Inovação crie um fundo próprio para investir na Ciência Aberta, que pode ser para a França ou para outras regiões. De acordo com o plano:

a) as publicações em acesso aberto devem ser controladas pela comunidade científica e não por editoras comerciais, bem como devem aderir aos princípios do open acess, que são a ética, a transparência, a governança e a propriedade intelectual;

b) as obras financiadas com recursos públicos devem estar publicadas em plataformas digitais de acesso aberto, pois são consideradas um bem público;

c) a sustentabilidade em longo prazo desse ecossistema está atrelada à avaliação de pesquisadores e instituições de pesquisa, pois ela regula a qualidade e não a quantidade de publicações. Como utiliza a Declaration on Research Assessment (Dora), a referida avaliação critica o atual sistema de avaliação dos pesquisadores, que faz uso do Fator de Impacto para analisar a produtividade dos pesquisadores (France, 2018). O papel das agências de fomento é adotar as políticas e, consequentemente, exigir os critérios para elegibilidade de propostas distribuição de recurso. Fica claro, no plano, que todas as esferas públicas estão interconectadas para que ele se desenvolva.

No Canadá, o Plano de Ciência Aberta faz parte de um plano maior para o Governo Aberto. As ações para a construção do Plano começaram em 2018, quando o Governo promoveu espaços para discussão e abriu a chamada pública para que a sociedade pudesse participar da construção do 2018-2020 National Action Plan on Open Government (Canada, 2018). Essa chamada obteve mais de 10 mil pessoas para ajudar na elaboração do plano, resultando em cerca de 5 mil ações. Os princípios para nortear as ações do Governo Aberto são inclusão, equidade de gênero, acessibilidade, pensamento centrado na pessoa, reconciliação (com a população indígena) e colaboração. O plano é desenvolvido com o propósito de elencar problemas, apontar ações e soluções e, por fim, definir os órgãos e parceiros responsáveis.

O Plano Nacional para o Governo Aberto do Canadá, ao incluir a Ciência Aberta, vai tratar de um problema importante, que se refere ao fato de que, até 2018, a ciência financiada pelo governo não é aberta e de fácil localização. Isso gera dificuldades para muitas pessoas que não sabem como encontrar as informações científicas de interesse, impedindo-as de colaborar (Canada, 2018).

O objetivo do plano é dar condições de viabilizar um roteiro para abertura a ciência nas instituições de pesquisa e agências de fomento. Ele criará um portal compreendendo as publicações e dados e relacionando-os com quem produziu, ou seja, no mesmo ambiente haverá uma rede social de cientistas federais, de modo que o cidadão poderá entrar em contato tanto com o pesquisador quanto com o conteúdo científico. O plano prevê a formação e o engajamento dos envolvidos (incluindo o cidadão), a criação de métricas e um fundo para desenvolver a Ciência Aberta (Canada, 2018).

No Brasil, as primeiras ações partiram do setor público e estão associadas a projetos globais. Uma das principais é a publicação da Lei n¹2.527/2011, de Acesso à Informação, dedicada principalmente a recursos para melhorar a transparência das instituições e do governo. Simultaneamente, nesse mesmo ano, houve colaboração entre diferentes governos. O Brasil, a Indonésia, o México, a Noruega, as Filipinas, a África do Sul, o Reino Unido e os Estados Unidos instituem uma parceria para desenvolver um Governo Aberto, denominada de Open Government Partnership (OGP), para promover um diálogo entre sociedade e governo para diminuir a corrupção, desenvolver políticas, soluções centradas no cidadão, engajando os governamenos e líderes da sociedade cívil para o desenvolvimento de políticas e ações em prol de governos mais inclusivos, responsívos e responsáveis (Open Government Partnership, 2019).

Em 2019, o OGP soma mais de 70 países aderidos a parceria e comprometidos a colaborar na construção de um plano para sua nação (Open Government Partnership, 2019). Um dos principais responsáveis para liderar a 
ação, no Brasil, é a Controladoria Geral da União (CGU), que desde então procura atingir as metas e mantém registro público de acordo com um plano de ação. Ela está, no referido ano, no 40 Plano de Ação Brasileiro (Brasil, 2018).

A Política Brasileira de Dados Abertos é uma das ações do Ministério do Planejamento, Desenvolvimento e Gestão (MP) para transformar digitalmente o governo brasileiro, sendo a publicação de dados abertos prevista no Decreto no 8.777, de maio de 2016 (Brasil, 2016). Em 2018, o Brasil foi considerado o oitavo país no ranking mundial de Dados Abertos da Open Knowledge Foundation (OKF), ranking que se baseia em temas como gastos do governo, legislação, meio ambiente, entre outros assuntos (Silva, 2018; World Ranking Open Data Open Knowledge Foundation, 2019).

Atrelado às ações para o Governo Aberto, está o plano para Ciência Aberta, que está em desenvolvimento pela CGU (Brasil, 2018) por meio do Grupo de Trabalho (GT), denominado de Inovação e governo aberto na ciência. Esse grupo é composto por membros da Empresa Brasileira de Pesquisa Agropecuária (Embrapa), do Instituto Brasileiro de Informação em Ciência e Tecnologia (IBICT/MCTIC/COEPE), da Coordenação de Aperfeiçoamento de Pessoal do Nível Superior (Capes), do Conselho Nacional de Desenvolvimento Científico e Tecnológico (CNPq), da Fiocruz, da Open Knowledge Foundation Brasil, da Associação Nacional de Pesquisa e Pós-Graduação em Ciência da Informação da UnB, Equipe de Monitoramento (CGU) e da Rede Nacional de Ensino e Pesquisa (RNP). O GT propõe um plano de ação (2018-2020) que envolve a implantação de uma rede interinstitucional pela Ciência Aberta, a definição de diretrizes, as articulações com agências de fomento, a criação de infraestruturas, os padrões de interoperabilidade e, enfim, os indicadores para aferição do grau de abertura da ciência.

Assim, entende-se que o País tem conduzido, de forma gradual e progressiva, alguns aspectos das dimensões da ciência aberta, sendo uma delas o acesso aberto. Há iniciativas de mais de 10 anos, como, por exemplo, os repositórios do Lume da UFRGS e Portal de Periódicos UFSC, ambos indicados anteriormente.

\section{Interpretando os antecedentes da Ciência Aberta no processo de produção científica}

Por ser estruturado, o sistema de produção científica sofre de males profundos, pois não garante que o conhecimento seja genuíno ou que a legitimação do conhecimento produzido seja igual à sua qualidade; restringe o acesso ao conhecimento e favorece seu controle por poucos; responde, em muitos casos, aos interesses das grandes corporações; divide a sociedade entre "quem sabe" (especialistas) e quem "não sabe" (outros); e, por fim, não inclui todos os atores envolvidos nos processos científicos.

O atual sistema de produção científica baseia-se na premissa de que as patentes e publicações em periódicos acadêmicos são as evidências mais relevantes dos avanços do conhecimento científico e do nível de produtividade dos pesquisadores. Os sistemas de avaliação e mensuração, por consequência, valem-se desse argumento, principalmente por meio de indicadores quantitativos.

Enfatiza-se que, na publicação de estudos em periódicos científicos, os pesquisadores devem cumprir os requisitos estabelecidos pelos órgãos avaliadores (agências de fomento, instituições, comitês etc.) normalmente vinculados à progressão de carreira do pesquisador. Ademais, os referidos órgãos estão alinhados a determinados parâmetros globais, como atingir certo índice h e publicar em periódicos que pertençam a editoras reconhecidas, com revisão por pares e certo fator de impacto, dando preferência para periódicos internacionais. O descumprimento desses critérios resulta num conjunto de sanções que envolvem condições econômicas e trabalhistas, progressão de carreira e até exclusão formal dos circuitos acadêmicos.

Lafuente e Alonso (2011, p.32) afirmam que os acadêmicos vivem da "economia de reputação: publicar ou morrer. Os cientistas são muito pressionados a produzir documentos que caiam no jogo de simulação: em vez de fazer um bom artigo a cada quatro anos, eles publicam quatro medíocres em um ano". Conforme o Prêmio 
Nobel de Medicina Randy Sheckman: "As principais revistas acadêmicas estão distorcendo o processo científico e representam uma 'tirania' que deve ser quebrada" (Sample, 2013, p.1).

A história de Évariste Galois (1811-1832), um eminente matemático francês, é um exemplo de como há uma distorção do impacto da produção científica no século XXI. Depois de ter trabalhos rejeitados pelas publicações, ele conseguiu publicar três textos que têm implicações para todos os ramos da matemática. Morreu com vinte anos, o que leva à reflexão de que "seu Índice H é dois e será assim para sempre, independentemente do impacto de seu trabalho" e de sua importância para a humanidade (Rigatelli, 2012, p.11).

Talvez nem Roland Barthes teria alcançado os atuais padrões para pertencer à comunidade científica, já que seu trabalho se espalhava principalmente por meio de jornais e ele escrevia da mesma forma que se escreve na área da antropologia. Os revisores dos comitês científicos provavelmente recomendariam que ele definisse sua linha de pesquisa e publicasse em periódicos de prestígio.

No que se refere ao produto da pesquisa financiada com dinheiro público e/ou um acadêmico vinculado a uma instituição pública, ele deve, por lei ou por política, ser abertamente acessível à sociedade, justamente porque foi esta quem contribuiu com recursos para seu desenvolvimento.

Importante salientar o caso das publicações nas revistas científicas que pertencem o grupo das editoras Elsevier; Wiley-Blackwell, Springer e Taylor \& Francis (Björk, 2017; Larivière; Haustein; Mongeon, 2015) as quais concentram o monopólio da distribuição do conhecimento científico no mundo, mantendo um negócio por meio das publicações dos periódicos acadêmicos. Se for considerado o caso de um acadêmico que trabalha em uma universidade pública, ou seja, cujo trabalho é pago com os impostos da sociedade e que publica em uma dessas revistas científicas para avançar em sua carreira acadêmica, haverá um caminho próprio a ser seguido: primeiramente, ele terá de pagar uma taxa para submeter o artigo na revista; em seguida, a universidade pagará quantias extraordinárias a esses editores acadêmicos, para que seus cientistas e estudantes possam ter acesso ao conhecimento atualizado; e, por fim, um cidadão sem vínculo com a academia e que queira ler o artigo deverá pagar ao editor.

Nesse sentido, tanto a universidade quanto o acadêmico contribuem - às vezes, sem pensar - para a privatização do conhecimento, uma vez que a pessoa que investiu na geração desse conhecimento - o cidadão - não tem livre acesso a ele. Cria-se um círculo vicioso que não beneficia quem deve se beneficiar: a sociedade em geral. Um exemplo de política apropriada a esse respeito é a da Universidade de Harvard, que adotou o acesso aberto às suas publicações por padrão.

Outra condição, cada vez mais frequente nas instituições, é a de que os pesquisadores atraiam recursos privados para seus projetos. Sob esse esquema, é necessário pensar criticamente sobre o papel dos pesquisadores que, em face do favor da "concessão", devem ajustar seus interesses e julgamentos à vontade da empresa. Segundo Andoni, Rodriguez e Lafuente (2013), 50\% dos ensaios clínicos não são publicados porque não "falam bem" de empresas farmacêuticas; o mesmo acontece no caso de especialistas que trabalham para uma multinacional sob a bandeira da saúde pública, visto que, em 34\% dos casos, há um conflito de interesses. Sob a bandeira da "quota de benefício" multiplicar os donos do conhecimento, usa-se a estratégia: "Eu faço você compartilhar os benefícios, mas você é um cúmplice na destruição do mundo".

No entanto, deve-se também questionar as alianças das instituições acadêmicas com empresas privadas (farmacêuticas, tecnológicas etc.) que financiam pesquisas, tendo em vista que o objetivo principal é gerar um benefício econômico para a empresa por meio de projetos que aparentemente têm interesse na produção de conhecimento e benefício social. Aaron Swartz afirmou que nada poderia ser alcançado quando se está na posição de "escravos da indústria privada. No campo acadêmico, isso implicaria na liberdade do domínio dos interesses 
monetários e da influência corporativa. Para a sociedade, diferentemente, é a representação de que a ciência realmente é um bem comum, um bem público e que, dentro desse contexto, o cidadão que investe em ciência terá seu espaço garantido na construção da Ciência Aberta porque a pesquisa, dentro desses princípios, deve ser elaborada com e para a sociedade (Anglada; Abadal, 2018).

\section{Novos rumos para pesquisadores}

Em geral, os pesquisadores são bastante conservadores em muitas de suas práticas. Os especialistas devem perceber que o conhecimento aberto não é uma resistência aos seus interesses, visto que pode lhes trazer mais vantagens do que inconvenientes.

A primeira virtude da Ciência Aberta, oriunda do acesso aberto à informação, é sua capacidade de aumentar o impacto e a disseminação das suas pesquisas. Embora seja verdade que atualmente os méritos de um cientista são avaliados pelo número de publicações, pela presença de seu trabalho em periódicos renomados e pelas citações de seu trabalho por outros pesquisadores, é também verdade que há dificuldade de acesso ao conteúdo, quando este está disponibilizado mediante pagamento de taxas.

Na avaliação de carreiras dentro da prática de Ciência Aberta, a Comissão Europeia (2017) se propôs a desenvolver um novo sistema para avaliação e progressão de carreira dos pesquisadores (Declaration on Research Assessment, 2018), em oposição ao modelo tradicional de avaliação de pesquisadores. Em resposta a esse desequilíbrio, pesquisadores publicaram a Declaration on Research Assessment de São Francisco, em 2012, para que os responsáveis pela promoção e seleção de pesquisadores não utilizassem o Fator de Impacto como indicador de qualidade, pois eles entendem que o local de publicação do autor não é determinante na qualidade do conteúdo publicado. A DORA é também uma manifestação mundial e pública de insatisfação com o modelo atual e registrou, em 2019, mais de 14.173 assinaturas individuais, além da participação de 1.336 organizações.

Se a questão de avaliação dos pesquisadores não estiver mais atrelada ao Fator de Impacto, os pesquisadores se sentirão mais motivados a publicar em acesso aberto, permitindo que mais pessoas de todas as classes acessem seu trabalho, leiam-no e o promovam. A resistência do pesquisador, a qual pode estar relacionada com a visibilidade do seu artigo, seguindo a máxima de que, estando em editoras comerciais, ele será mais citado, não é consistente com o trabalho de Larivière, Haustein e Mongeon (2015), que analisaram por 10 anos os periódicos científicos das quatro maiores editoras comerciais: Elsevier; Wiley-Blackwell; Springer e Taylor \& Francis perceberam um aumento na média de citações nos primeiros três anos de inserção, que seguiram em queda nos anos seguintes. "Isso indica que há pouco ou nenhum aumento no número de citações quando um periódico científico é incluído" em tais bases (Silveira; Benedet; Santillán-Aldana, 2018, p.101).

Dessa forma, o trabalho publicado em acesso aberto pode ter ainda mais relevância do que o publicado de modo tradicional, em periódicos de acesso restrito. É necessário, portanto, que as instituições de pesquisa e as agências de fomento e de avaliação do pesquisador reconheçam os méritos de um cientista também com base nas publicações em acesso aberto que ele faz. Sem reforço, poucos pesquisadores ousam dar esse passo.

Outro ponto, a que muitos pesquisadores resistem, relaciona-se com o copyright, ou direitos autorais, no caso brasileiro. Publicar em periódicos de acesso aberto não significa perder a autoria ou os méritos do estudo. Perde-se mais quando se publica de maneira tradicional porque, a depender da política editorial, os editores exigem que os direitos do trabalho sejam cedidos por um período definido ou que pode, até, vir a ser vitalício. Caso seja por um período vitalício, dependendo do contrato, há casos em que o pesquisador-autor do conteúdo precisa comprar sua obra para utilizá-la. O conteúdo em acesso aberto pode ser protegido por meio das licenças Creative Commons ou Science Commons, que permitem o ajuste dessa licença conforme o interesse do autor ou da instituição de conceder o direito de usar, distribuir, remixar as informações. 
Por fim, sabe-se que há outra desvantagem em relação aos modelos tradicionais, visto que não há negócios fáceis. Da mesma forma que a indústria fonográfica não recebe tanto dinheiro devido à pirataria, os editores científicos o perdem em decorrência do acesso aberto e de sua gratuidade. Por esse motivo, nos últimos anos, o aumento considerável de assinaturas para acesso à informação compensou as perdas (das editoras). Apesar disso, eles têm notado que é necessário se adaptar às novas formas de acesso ao conhecimento; muitos já estão ajustando seu modelo de negócio por meio da promoção, cada vez maior, de benefícios/serviços para os pesquisadores.

\section{Considerações Finais}

Uma das maiores preocupações entre os envolvidos na produção científica é a questão ética. Uma ética da produção e difusão do conhecimento de maneira aberta e compartilhada vai contra a lógica do sistema financeiro global, mas pode contribuir para contrabalançar as desigualdades em termos de concentração de informação, conhecimento e capital. A adoção de informação aberta como política universal para a promoção de conhecimento, de modo a contribuir para o desenvolvimento da humanidade, para a criatividade, a inovação, a formação de memórias coletivas e diversos imaginários, deve fazer parte das prioridades do Brasil e de suas regiões.

Há uma carência, por parte dos governos e das instituições, quanto ao aprofundamento nos temas que envolvem a ética dos monopólios editoriais na produção e na circulação do conhecimento. É necessário que promovam políticas públicas transparentes que invistam no desenvolvimento científico e tecnológico desde sua abertura.

A presença da Ciência Aberta em todas as áreas disciplinares ainda não é uma prática estabelecida, e sua integração nas comunidades científicas continua a ser um desafio, pois a Ciência Aberta assume várias formas. O acesso aberto a publicações de pesquisa representa apenas uma das etapas necessárias à Ciência Aberta como um todo, que ainda está longe de seu pleno potencial, visto que isso requer uma transformação substancial com base nos princípios de transparência, compartilhamento e colaboração.

Os novos modelos quantitativos e qualitativos de avaliação da pesquisa devem refletir e promover uma atitude nova em relação aos envolvidos. Isso evidencia que a busca por melhores formas de avaliação está se tornando cada vez mais importante para a comunidade cientíica em geral e para uma variedade de formuladores de políticas nacionais. As novas abordagens voltadas para a avaliação da pesquisa refletem a necessidade urgente de mudar o atual paradigma para além do fator de impacto típico da revista, porque não se trata do local em que se publica, mas o que se publica, isto é, deve ser dada importância ao conteúdo e à sua relevância para área. O desenvolvimento de novas maneiras de avaliar o pesquisador está intrinsecamente ligado à transição para a Ciência Aberta e isso requer dele atitudes simples, como dar preferência a publicações em fontes de informação que zelem pela essência da Ciência Aberta: o bem comum.

Uma das necessidades do desenvolvimento da Ciência Aberta é o investimento não apenas em infraestruturas políticas e tecnológicas, mas principalmente em recursos humanos com competências fundamentais para a implementação de serviços com vistas a amparar o cientista em cada fase do ciclo de pesquisa. Isso porque essa ação não consiste apenas em transferir todas as responsabilidades ao pesquisador, mas sim dar ferramentas e condições para que ele construa esse novo modo de fazer ciência com mais transparência, ética e colaboração.

\section{Colaboradores}

Ambos os autores colaboraram com a concepção, desenho, análise, revisão e aprovação final do ensaio. 


\section{Agradecimentos}

São feitos agradecimentos a Capes, Universidade Federal do Rio Grande do Sul e Universidade Federal de Santa Catarina pelo apoio em infraestrutura de fontes de informação para a realização da presente pesquisa.

\section{Referências}

Andoni, A.; Rodríguez, J.; Lafuente, A. Todo sabio, ciencia ciudadana y conocimiento ampliado. Madri: Ediciones Cátedra, 2013.

Anglada, L.; Abadal, E. ¿Qué es la ciencia abierta? Anuario Thinkepi, v.12, p.292-298, 2018. Doi: http://dx.doi.org/10.3145/ thinkepi.2018.43. Disponible en: https://recyt.fecyt.es/index. php/ThinkEPI/article/view/thinkepi.2018.43. Acceso en: 6 mayo 2019.

Bartling, S.; Friesike, S. (Org.). Opening science. New York: Springer, 2014. p.17-47. E-book. Available from: https://link. springer.com/book/10.1007/978-3-319-00026-8. Cited: May 6, 2019

Berners-Lee, T. Linked data. World Wide Web Consortium, 2006. Available from: http://www.w3.org/Designlssues/ LinkedData.html. Cited: May 6, 2019

Björk, B.C. Scholarly journal publishing in transition- from restricted to open access. Electronic Markets, v.27, n.2, p.101109, 2017. Available from: http://link.springer.com/10.1007/ s12525-017-0249-2. Cited: Aug. 18, 2019.

Brasil. Presidência da República. Decreto n8.777, de 11 de maio de 2016. Institui a Política de Dados Abertos do Poder Executivo Federal. Diário Oficial da União, 2016. Disponível em: http://www.planalto.gov.br/ccivil_03/_ato2015-2018/2016/ decreto/D8777.htm. Acesso em: 12 maio 2016.

Brasil. Ministério da Transparência e Controladoria-Geral da União. 40 Plano de Ação Nacional em Governo Aberto. Brasília: Open Government Partnership, 2018. Disponível em: http:// governoaberto.cgu.gov.br/no-brasil/copy_of_planosde-acao/4o-plano-de-acao-brasileiro/4o-plano-de-acaonacional_portugues.pdf. Acesso em: 6 maio 2019.

Budapest Open Access Initiative. Budapest Open Access Initiative. Budapeste: BOAl, 2002. Available from: http://www. opensocietyfoundations.org/openaccess/read. Cited: May 6, 2019.

Canada. Government of Canada. 2018-2020 National Action Plan on Open Government. 2018. Available from: https://open. canada.ca/en/content/canadas-2018-2020-national-actionplan-open-government. Cited: May 6, 2019.

Declaration on Research Assessment. Good practices. San Francisco: DORA, 2018. Available from: https://sfdora.org/ good-practices/funders/. Cited: May 6, 2019.

Elsevier. Acesso aberto. Holanda: Elsevier, 2019 Disponível em: https://www.elsevier.com/pt-br/about/open-science/openaccess. Acesso em: 6 maio 2019.

France. Ministère de L'Enseignement supérieur de la Recherche et de L'Innovation. National plan for open science.
Paris: Open Science, 2018. Disponible en: https://libereurope. eu/wp-content/uploads/2018/07/SO_A4_2018_05-EN_ print.pdf. Acèss: mayo 6, 2019.

Foster Open Science. Open science taxonomy. [s.l.]: Foster, 2018. Available from: https://www.fosteropenscience.eu/ foster-taxonomy/open-access. Cited: May 6, 2019.

Lafuente, A.; Alonso, A. Ciencia expandida, naturaleza común y saber profano. Quilmes: Universidad Nacional de Quilmes, 2011.

Larivière, V.; Haustein, S.; Mongeon, P. The oligopoly of academic publishers in the Digital Era. PLO ONE, v.10, n.6, e0127502, 2015. Available from: http://dx.org/ 0.1371/journal. pone.0127502. Cited: Aug. 26, 2019.

Nüst, D. et al. Reproducible research and GIScience: An evaluation using AGILE conference papers. PeerJ, v.6, e5072, 2018. Doi: http://dx.doi.org/10.7717/peerj.5072. Available from: https://peerj.com/articles/5072/. Cited: May 6, 2019.

Open Government Partnership. Open Government Partnership Global Report: democracy beyond the ballot box. Canada: OPG, 2019. Available from: https://www.opengovpartnership. org/wp-content/uploads/2019/05/Global-Report_Volume-1. pdf. Cited: May 6, 2019.

Pontika, N. et al. Fostering Open Science to Research using a Taxonomy and an eLearning Portal. In: International Conference on Knowledge Technologies and Data Driven Business (iKnow), 15., 2015, Graz, Austria. Procedings [...] New York: ACM, 2015. Doi: http://dx.doi.org/doi:10.1145/28 09563.2809571. Available from: http://oro.open.ac.uk/44719/ 2/kmi_foster_iknow.pdf. Cited: May 6, 2019.

Relx Group. Annual reports and financial statements: 2018. London: Relx, 2018. Available from: https://www.relx.com/ investors/annual-reports/2018. Cited: May 6, 2019.

Rigatelli, L.T. Evariste Galois 1811-1832. Switzerland: Birkhäuser, 2012.

Ross-Hellauer, T. What is open peer review? A systematic review. F1000Research, v.6, 588, 2017. Doi: http://dx.doi.org/10. 12688\%2Ff1000research.11369.1. Available from: https://f10 00research.com/articles/6-588. Cited: May 6, 2019.

Ross-Hellauer, T.; Deppe, A.; Schmidt, B. Survey on open peer review: Attitudes and experience amongst editors, authors and reviewers. PLoS One. v.12, n.12, e0189311, 2017. Doi: http:// dx.doi.org/10.1371/journal.pone.0189311. Available from: https:// journals.plos.org/plosone/article?id=10.1371/journal.pone. 0189311. Cited: May 7, 2019.

Sample, I. Nobel winner declares boycott of top science journals. The Guardian, Dec. 9, 2013. Available from: https:// www.theguardian.com/science/2013/dec/09/nobel-winnerboycott-science-journals. Cited: May 7, 2019. 
Schmidt, E.; Cohen, J. A nova era digital: como será o futuro das pessoas, das nações e dos negócios. Rio de Janeiro: Intrínseca, 2013.

Silva, D.M. et al. Comunicação científica sob o espectro da Ciência Aberta: um modelo conceitual contemporâneo. Revista Eletrônica de Comunicação, Informação \& Inovação em Saúde, v.11, 2017. Suplemento. Doi: http://dx.doi.org/10. 29397/reciis.v11i0.1414. Disponível em: https://www.reciis icict.fiocruz.br/index.php/reciis/article/view/. Acesso em: 7 maio 2019

Silva, F.C.C. Movimento open data em bibliotecas: desafios e oportunidades. In: Seminário do Grupo de Pesquisa MHTX: perspectivas em representação e organização do conhecimento: atualidades e tendências na relação universidade-empresa, 3., Belo Horizonte, Brasil. Anais [...] Belo Horizonte: ECI/UFMG, 2018.

Silveira, L.; Benedet, L.; Santillán-Aldana, J. Interpretando a internacionalização dos periódicos científicos brasileiros.
Motrivivência, v.30, n.54, p.90-110, 2018. Doi: http://dx.doi. org/10.5007/2175-8042.2018v30n54p90 Disponível em: https:// periodicos.ufsc.br/index.php/motrivivencia/article/view/21 75-8042.2018v30n54p90. Acesso em: 7 maio 2019.

Spinak, E. Sobre as vinte e duas definições de revisão por pares aberta... e mais. SciELO em Perspectiva, 2018. Disponível em: https://blog.scielo.org/blog/2018/02/28/sobre-as-vintee-duas-definicoes-de-revisao-por-pares-aberta-e-mais/. Acesso em: 15 fev. 2019.

Wilsdon, J. et al. Next-generation metrics: Responsible metrics and evaluation for open science. Luxembourg: Publications Office of the European Union, 2017. Doi: http://dx.doi. org/10.2777/337729 Available from: https://ec.europa.eu/ research/openscience/pdf/report.pdf. Cited: May 7, 2019.

World Ranking Open Data Open Knowledge Foundation. Place overview. Canada: GODI, 2019. Available from: https:// index.okfn.org/place/. Cited: May 7, 2019. 